reasonable range of clinical activities, coverage of the population for preventive initiatives, patient satisfaction, and the satisfaction and learning opportunities of the practice's staff. Doctors should be prepared to describe such audits and, in broad terms, the findings and their future plans to the Medical Audit Advisory Group, which should then reach an opinion as to the range and rigour of the audits undertaken.

External audit would have to be much more of a broad brush stroke affair-simply because the expense of any meaningful detailed examination of a practitioner's work would be prohibitive. "Mainstream" practices with an audit programme as outlined above could be left to their own devices or sometimes given some new ideas about aspects of care to examine or instruments (such as outcome measures) with which to do it. "Outliers," though annoying to the tidy minded manager, might turn out to be at the head or the tail of the caterpillar. Such outside observers will need to consider how far the local circumstances (deprivation, affluence, ethnic mix, and so on) might account for "aberrant" behaviour before any assumptions are made about effectiveness, effi- ciency, or acceptability. The circular says that Medical Audit Advisory Groups will "analyse local audit results and discuss them with the local medical committees," but it makes no warnings about being careful to compare like with like. Even with earmarked resources the Medical Audit Advisory Groups will have limited abilities: if they are to have an impact on the "tail end" of general practice they must not be spread too thin over the whole range. Nor must their inquisitiveness impede the curiosity and innovativeness of the progressive practices (whose contributions as leaders have been the best justification for the independent contractor status).

Audit is a precise and scientific term describing a well defined and rigorous discipline. Medical audit is needed in the family practitioner services and it should be welcomedprovided that politicians, administrators, managers, and doctors all accept that they have an obligation to be rational about it.

D H H METCALFE

Professor of General Practice,

University of Manchester, Manchester M13 9PL

\title{
The cyclotron saga continues
}

\section{Advisers advise, the Prime Minister decides}

Last year's government decision to provide a donation of $£ 6 \mathrm{~m}$ towards the building of a cyclotron at St Thomas's Hospital aroused furious hostility in the main cancer funding agencies and provoked a flurry of correspondence in both the $B M \mathcal{F}$ and the national press..$^{1-3}$ The decision itself was made in order to make irradiation treatment with fast neutrons available again for cancer patients in London after the discontinuation of such treatment at the Hammersmith Hospital in 1984. The Department of Health repeatedly announced its conviction that the clinical results had confirmed that neutron therapy was of established benefit in certain types of cancer and should be made more widely available to NHS patients.

The profession's response to what the government clearly regarded as an imaginative step seems to have piqued the Department of Health, though the then health minister, $\mathrm{Mr}$ David Mellor, did agree to meet senior representatives of the United Kingdom Coordinating Committee for Cancer Research, the Medical Research Council, the Cancer Research Campaign, and the Imperial Cancer Research Fund. Despite strong protests that the $£ 6 \mathrm{~m}$ sum could be much better used for other purposes the department refused to change its stance. A Medical Research Council survey of neutron trials in Britain had already been set up to examine in detail whether the Hammersmith claims (greater efficacy of neutron beam therapy as compared to conventional $x$ ray treatment tested in a multicentre setting) could be reconciled with the Edinburgh experience more recently reported.+.9 This trial, carried out in a single centre between 1977 and 1984 , had shown no clinical benefit for neutron therapy in a prospective randomised study of 185 patients. The authors were aware of substantial and irreversible late complications of neutron therapy in patients treated at the Hammersmith and had reduced the dose they used in order to avoid these. Yet nevertheless, the patients in Edinburgh treated with neutrons showed neither superior control nor longer survival than patients treated conventionally; and, sadly, the neutron group clearly had worse long term morbidity with six deaths related to treatment. The Medical Research Council's analysis confirmed for the first time that serious complications and even treatment deaths in the Hammersmith patients were by no means rare, with 10 identified fatalities (close to $20 \%$ of the treated group). Moreover, profound irreversible damage to normal tissues from neutron beam therapy has recently been highlighted by surgical groups who have been called in to attempt to repair such massive damage. They report persistent ulceration, trismus, and other features of treatment related fibrosis, as well as radionecrosis and fistula to a degree not previously encountered (D M Davies, personal communication). Such cases are extremely difficult to repair successfully and generally require major "three dimensional" resection leading to a mediocre cosmetic result and permanent functional defects.

Much of this more recent evidence was described in a recent $\mathrm{BBC}$ radio programme, Face the facts, which has been widely discussed and has served to keep this debate alive. It has also emerged in recent months that the National Cancer Institute in the United States and other funding bodies in Europe have decided to discontinue funding for neutron programmes. The current position in Britain is that the neutron facility at Clatterbridge Hospital in Merseyside continues to recruit patients into its important prospective study, but we now have the prospect of a further neutron programme in London - provided that the Cyclotron Trust, which was so successful at persuading Mrs Thatcher and the Department of Health to part with $£ 6 \mathrm{~m}$, proves equally effective in its search for an additional $£ 4 \mathrm{~m}$ from other charitable sources.

Neutrons may possibly have a part to play in the management of a few specific tumours such as salivary cancers, melanoma, and soft tissue sarcomas, ${ }^{10}$ but the case still remains unproved, and the side effects related to treatment seem clearly more severe than with photons - at least with doses currently employed.

By her own admission Mrs Thatcher has taken a personal interest in this current debate. She has chosen to ignore the overwhelming body of evidence and advice rendered her by dispassionate parties equally concerned to identify any 
possible advance in cancer care but more cautious in the spending of public money. Since well conducted studies give such little support for neutron therapy as a superior or even equal treatment to conventional radiotherapy there cannot be any further justification for continuing with this ill advised venture.

Consultant Clinical Oncologist,

J S TOBIAS

University College Hospital,

London WC1E 6AU

I Smith R. Radiotherapy's second setback. Br Med f 1988;297:1625-6.

2 MacDougall RH. Cyclotron project. The Times 1988 Oct 29:11.

3 Goolden AWG, Munro AJ. Neutron therapy. Independent 1988 Oct 31:21.
4 MRC Neutron Therapy Working Group. A comparative review of the Hammersmith (1971-75) and Edinburgh (1977-82) neutron therapy trials of certain cancers of the oral cavity, oropharynx, larynx and hypopharynx. Br F Radiol 1986;59:429-40.

5 Catterall $M$, Sutherland I, Bewlev DK. First results of a randomised clinical trial of fast neutron compared with $x$ or gamma ravs in treatment of advanced tumours of the head and neck. Br.Med 1975;ii:653-6.

6 Catterall M, Bewley DK, Sutherland I. Second report on results of a randomised clinical trial of fast neutrons compared with $x$ or gamma ravs in treatment of advanced tumours of head and neck. Br.

7 Duncan $\mathrm{W}$, Arnott SJ, Orr JA, Kerr GR. The Edinburgh experience of fast neutron theraps. Int $\mathcal{F}$ Radiat Oncol Biol Phys 1982;8:2155-7.

8 Duncan W, Orr JA, Arnott SJ, et al. Fast neutron therapy for squamous carcinoma in the head and neck region: results of a randomised trial. Int $\mathcal{F}$ Radiat Oncol Biol Phys 1987;13:171-8.

9 MacDonald RH, Orr JA, Kerr GR. Neutron therapy for squamous cell carcinoma of the head and neck: the 5 year follow up of the Edinburgh randomized clinical trial. Proceedings of the British Oncology Association 1989;4:1

10 Griffin TW, Pajak TF, Laramore GE, et al. Neutron vs photon irradiation of inoperable salivary gland tumours: results of an RTOG-MRC cooperative randomised study. Int 7 Radiat Oncol Biol Phys 1988;15:1085-90.

\section{Regular Review}

\section{Monitoring the prevalence of HIV}

\section{Foundations for a programme of unlinked anonymous testing in England and Wales}

This month the Department of Health has announced plans for extensive testing for HIV of unlinked anonymous blood samples taken from patients in England and Wales. This review sets out the scientific, legal, and ethical basis for such a programme.

In England and Wales by the end of October 1989 some 2717 cases of AIDS had been reported confidentially by clinicians directly to the Public Health Laboratory Service AIDS centre and 1422 of these patients were known to have died (Public Health Laboratory Service, Communicable Disease Report 1989/44). The number of persons estimated to be infected with HIV at the end of 1987 was between 20000 and 50000; among these another 16000 to 40000 will probably develop AIDS in the next 10 to 15 years.

Indirect evidence suggests that the rate of HIV transmission in behaviourally vulnerable groups such as homosexual or bisexual men ${ }^{2}$ and intravenous drug users ${ }^{3}$ may have declined. Though transmission of HIV through heterosexual contact is probably increasing (ON Gill et al, International Conference on AIDS, Montreal, 1989), it is uncertain whether transmission solely by such contact will produce a self sustaining HIV epidemic throughout the whole or parts of heterosexually active society in England and Wales. ${ }^{+}$Such uncertainties about a major epidemic of largely fatal infection make it imperative that surveillance methods be reviewed regularly.

\section{Present methods}

At present in England and Wales serosurveillance for HIV infection relies on aggregating data collected as a byproduct of case finding by using either the named ${ }^{35-9}$ or mandatory ${ }^{10}$ test methods (table). The informed consent of the patient is required in all but the most exceptional circumstances before testing a named specimen for HIV in all but the most exceptional circumstances (General Medical Council statement "HIV infection and AIDS: the ethical considerations," May, 1988). The mandatory tests of blood donors are also named, but donors can choose not to give blood and people at special risk behaviourally have since 1983 been encouraged not to donate (National Blood Transfusion Service leaflet "AIDS and how it concerns blood donors").

Serosurveillance for HIV should aim at obtaining unbiased estimates of the change in the prevalence of infection with time and by age, sex, place, and exposure category. Two forms of bias affect the interpretation of this type of case finding data. ${ }^{18}$ Firstly, participation bias occurs when members of the study population differ in an important way from non-participants; for example, it affects universal named case-finding programmes. ${ }^{9}$ Secondly, selection bias occurs when the study population is not representative of the population for which conclusions from the study are to be drawn; mandatory screening of blood donors is particularly

Approaches to HIV serosurveillance

\begin{tabular}{|c|c|c|c|c|}
\hline \multirow[b]{2}{*}{ Objective } & \multirow[b]{2}{*}{ Methods } & \multicolumn{2}{|c|}{ Bias } & \multirow[b]{2}{*}{ Examples } \\
\hline & & Participation & Selection & \\
\hline \multirow[t]{4}{*}{ Case finding ${ }^{\star}$} & Selective named & + & \pm & $\begin{array}{l}\text { Laboratory reports of HIV infection, }{ }^{356} \text { ad hoc studies, }{ }^{7} \text { PHLS } \\
\text { collaborative laboratory study of HIV } \text { tests }^{8}\end{array}$ \\
\hline & Universal named & ++ & \pm & $\begin{array}{l}\text { PHLS collaborative study of patients attending clinics for sexually } \\
\text { transmitted diseases }\end{array}$ \\
\hline & Linked anonymous & ++ & \pm & $\begin{array}{l}\text { Alternative site HIV testing programme" (J C Grabau et al, International } \\
\text { Conference on AIDS, Stockholm, 1988) }\end{array}$ \\
\hline & Mandatory & & ++ & Blood donor screening ${ }^{10}$ \\
\hline \multirow[t]{2}{*}{ Prevalence monitoring } & Unlinked anonymous & & \pm & $\begin{array}{l}\text { Studies conducted in London }{ }^{12 \cdot 16}(\text { R S Tedder } e t a l \text {, International } \\
\text { conference on AIDS, Montreal, 1989) }\end{array}$ \\
\hline & Unlinked anonymous: voluntary $\star \star$ & \pm & \pm & Needle exchange project in central London ${ }^{17}$ \\
\hline
\end{tabular}

^ All case finding methods are voluntary.

$\star \star$ If a special specimen is collected (for example, saliva) then the study method must be voluntary. 